\title{
An LGBTQ-Inclusive Problem Set in Discrete Mathematics
}

\author{
Trysten Scott Richard \\ School of Computing \\ University of Utah \\ Salt Lake City, UT, USA \\ TSRichard95@gmail.com
}

\author{
Eliane S. Wiese \\ School of Computing \\ University of Utah \\ Salt Lake City, UT, USA \\ eliane.wiese@utah.edu
}

\author{
Zvonimir Rakamarić \\ School of Computing \\ University of Utah \\ Salt Lake City, UT, USA \\ zvonimir@cs.utah.edu
}

\begin{abstract}
This project aims to improve LGBTQ (lesbian, gay, bisexual, trans, and queer) representation in the University of Utah's discrete mathematics course. Many practice problems in the course textbook rely on heteronormative and/or cisnormative premises. We developed alternatives that maintained the original mathematical content while including minority identities, and then deployed them in a homework assignment. Students also completed a survey on their opinions of the new questions. Most students were open to the inclusion of LGBTQ representation in their homework, and many applauded it. However, students also suggested that subtle wording was preferable, and that affirming problems should be sprinkled across the course rather than concentrated in one assignment. Our experience provides an example of framing mathematical content to support an inclusive classroom climate, and we expect that our lessons learned can inform assignments that affirm minority identities throughout the CS curriculum.
\end{abstract}

\section{CCS CONCEPTS}

- Social and professional topics $\rightarrow$ Computer science education; Sexual orientation; Gender.

\section{KEYWORDS}

inclusivity; LGBTQ; sexual minority; instructional design

\section{ACM Reference Format:}

Trysten Scott Richard, Eliane S. Wiese, and Zvonimir Rakamarić. 2022. An LGBTQ-Inclusive Problem Set in Discrete Mathematics. In Proceedings of the 53rd ACM Technical Symposium on Computer Science Education V. 1 (SIGCSE 2022), March 3-5, 2022, Providence, RI, USA. ACM, New York, NY, USA, 7 pages. https://doi.org/10.1145/3478431.3499330

\section{INTRO: NOTICING THE PROBLEM}

A core topic in discrete mathematics for computer scientists is combinatorics. A sample problem from our course textbook, Discrete Mathematics: Mathematical Reasoning and Proof with Puzzles, Patterns, and Games [9], describes members of an organization forming committees: "there are 20 married couples and there is a rule prohibiting spouses from serving on the same committee. How many five-man, four-woman committees can be formed under this new restriction?"

Permission to make digital or hard copies of all or part of this work for personal or classroom use is granted without fee provided that copies are not made or distributed for profit or commercial advantage and that copies bear this notice and the full citation on the first page. Copyrights for components of this work owned by others than the author(s) must be honored. Abstracting with credit is permitted. To copy otherwise, or republish, to post on servers or to redistribute to lists, requires prior specific permission and/or a fee. Request permissions from permissions@acm.org.

SIGCSE 2022, March 3-5, 2022, Providence, RI, USA

(C) 2022 Copyright held by the owner/author(s). Publication rights licensed to ACM ACM ISBN 978-1-4503-9070-5/22/03 ..\$15.00

https://doi.org/10.1145/3478431.3499330
This problem, like many textbook combinatorics problems, uses a heteronormative framing. That is, the problem relies on the assumption that all marriages are heterosexual, consisting of one man and one woman. During a lecture, Rakamarić, who has taught this course several times, suddenly noticed the heteronormativity of the textbook problems he was using as in-class exercises. On the spot, he changed the problems to make them more LGBTQ-inclusive. The subsequent informal feedback he received was quite positive, especially from a trans student in the class:

[...] Mostly, I would like to thank you for being a conscientious teacher. Very rarely do I encounter professors outside the Gender Studies department [who] point out heteronormative and/or gender binary assumptions. As a transman, these things are often on my mind, and it was incredibly meaningful to have you bring up these subjects.

The impact for this student of the revised problems motivated our creation of affirming homework questions for the course.

We developed and deployed LGBTQ-affirming homework problems and gauged students' reactions through a survey. The combinatorics problems align mathematically with the originals, while including LGBTQ people in the problem contexts. Though most students felt positive or neutral about the new problems, many recommended subtle wording and having a few such problems in each assignment, rather than putting many of them in one homework. We hope our experience and lessons learned are helpful to others striving to make their classrooms welcoming for all students.

\section{PRIOR WORK: LGBTQ INCLUSION IN STEM}

Supporting diversity through CS course content is a priority for the SIGCSE community, evidenced by BoF sessions $[2,13,18]$ and a recent repository of inclusive assignments [28]. While many efforts to broaden participation focus on women in computing, recent work calls for more attention to queer identities, including trans and nonbinary genders [14]. Supporting LGBTQ students is particularly important, as they are more likely than their cis/straight peers to leave the CS major [26] and CS jobs [24] due to low sense of belonging and/or outright bullying. Yet, while the marginalization of LGBTQ college students is recognized $[6,10,17]$, LGBTQ-inclusion in CS course content is understudied.

Research on LGBTQ high school students indicates that inclusive curricula promote more welcoming and physically safer school environments (e.g., from bullying) [5, 15, 25]. While limited, the research on incorporating LGBTQ-inclusive curricula into postsecondary STEM education suggests that it can improve learning outcomes $[8,21]$. In particular, DiPietro's statistics course exclusively examines LGBTQ issues, such as the challenges of sampling 
the LGBTQ population in the US [8]. This curriculum both reduces stereotypical thinking and compellingly teaches applied statistics.

Diversifying a curriculum can involve varying degrees of depth, from simple representation (e.g., including a child with two dads in a story problem) to challenging the heteronormative status quo (e.g., considering new ways of defining "family") [19]. Banks [1] describes four tiers of integration, where the lowest two recognize contributions of marginalized communities and add related content within an existing pedagogical structure. The highest two involve full transformation of the curriculum around new perspectives and action to apply the concepts learned to social change. While initially proposed for multicultural education, Banks' tiers have also guided the design of inclusive LGBTQ curricula [15].

Our curricular changes operate on the lower tiers of Banks' hierarchy: we included LGBTQ concepts and individuals in story problems without altering the overall structure or goals of the course. While this approach will not achieve the full potential of CS classes to examine and address social issues (e.g., [16]), it is also easier (and therefore more likely) for instructors to implement.

\section{LGBTQ-AFFIRMING COMBINATORICS}

Our discrete mathematics textbook [9] relies on cisnormative pronouns and heteronormative example scenarios (sample question in section 1). Problems often describe groups as being necessarily composed entirely of men and/or women, making no mention of transgender, non-binary, or intersex individuals (cisnormative), and assume that all couples consist of one man and one woman, ignoring other gender configurations (heteronormative). Although cis/hetero-normative questions appeared most frequently in the sections on Combinatorics and Probability, they are present in six of the seven chapters.

We give abbreviated examples ${ }^{1}$ of our inclusive questions next:

(1) Charlie and her girlfriend, Amber, go to lunch at a restaurant with 7 sandwiches and 5 drinks on the menu. How many possible two-sandwich, two-drink meals can they order (regardless of which of them orders first) if they order different sandwiches and drinks from each other?

(2) You conduct an experiment in which you interview a large number of families, each of which has 5 children. For each family, you write down the biological sex ( $M$ for male, $F$ for female, I for intersex) of the children, in order from oldest to youngest. How many possible results are there?

(3) A group of students is surveyed about race and gender identity for research purposes. The survey lists 6 categories for race and 4 categories for gender. How many different survey results are possible if students are allowed to check 1 vs. 2 boxes for race and 1 vs. 2 for gender?

Context and Positionality. Although a majority of Utahns support marriage equality [12], GLSEN reports that "most LGBTQ students in Utah experienced anti-LGBTQ victimization at school" [11]. Richard (they), a queer game design student, wants to use pedagogical principles to improve the learning experiences of minority students and support students' varied interests in computing. Wiese (she), a straight ally, focuses on integrating inclusivity with mathematics cognition. Rakamarić (he), a straight ally, wants to make the

\footnotetext{
${ }^{1}$ We publicly released the full problem set and survey [22].
}

classroom more inclusive for LGBTQ students, but does not have specific expertise on inclusivity.

\section{ASSIGNMENT \& SURVEY DEPLOYMENT}

Rakamarić included six minority-affirming questions on a problem set assigned as homework: the three presented in section 3, one on forming a committee for a diversity club (shown in section 5.1), one on ordering the letters LGBTQIA with various constraints, and one on forming a 3-person voting rights task force from a 15person group. The assignment also included six typical problems: three without humans, one with stereotypically gendered names (fack and fill) but no explicit gender indications, one with a male baseball player with he/him pronouns, and one with an explicit binary where each student in class provides "his or her" birthday.

\subsection{Course Enrollment and Demographics}

The Discrete Mathematics course had 220 students. According to the university's demographic survey, $19 \%$ were female and $81 \%$ were male (the survey options do not include non-binary genders). This course is required for the Computer Science major. 192 / 220 students (87\%) submitted solutions for the combinatorics assignment. This rate is typical; since one homework is dropped, most have 190-200 submissions. Although we do not have a controlled comparison of the difficulty between the inclusive problem set and a typical one, the assignment grades were consistent with expectation, indicating that the difficulty was not dramatically different from prior years. Rakamarić reviewed students' Piazza questions about the homework, and found no noticeable difference in quantity compared to other assignments (none of students' Piazza posts pertained directly to inclusivity). The course teaching assistants supported the inclusivity of the homework, and noted that all student comments to them about the inclusivity were positive.

\subsection{Survey Design}

A survey asked students if they noticed the affirming problems and what they thought of them. Exact question wordings are presented with their respective results in section 5 . To obtain context about the role of student identity in the class, our survey asked students for their age, sexual orientation, and gender. Following established best practices for inclusive survey design [7, 20,23], we used openresponse formats for the identity questions rather than multiple choice, and only asked students to self-identify factors that were directly relevant to our research. Of the 184 respondents, 153 (83\%) self-identified as straight/heterosexual, and 27 (15\%) as lesbian, gay, bisexual, or another orientation (4 declined to self-identify); 148 $(80 \%)$ self-identified as male/man, $33(18 \%)$ as female/woman, and 1 as genderqueer (2 declined).

This survey was offered to students as an optional, online Canvas quiz for a small amount of extra credit. The survey was anonymous: the instructor could see who completed the survey (to award extra credit), but students' identifiers were not connected to their responses. Therefore, we cannot tell which respondents completed the assignment. The survey was available through the course website for one week after the inclusive homework was due. 184 / 220 students (84\%) participated in the survey; 172 of these students had 
submitted a homework solution. Our IRB determined this work was non-human subjects research (submission \#00140880).

\section{SURVEY RESULTS \& ANALYSIS}

For multiple-choice questions, we report how many students selected each option. To analyze open responses, we used thematic analysis [4]: for each question, Richard read all responses and generated an initial list of codes based on emergent themes. All authors participated in iterative coding sessions to review the themes and collapse categories or generate new ones as needed to reflect the nuances of the responses. We segmented the responses that included multiple ideas so that each idea could be coded separately. We present the themes, the student responses they cover, and representative quotations (verbatim except for square brackets).

\subsection{Initial Reactions - Multiple Choice}

The first question asked Did you notice that some of the problems on your most recent homework emphasized inclusiveness regarding gender and sexual orientation? Most students did notice - multiplechoice (MC) responses were Yes: 171 (93\%), No: 7 (4\%), Unsure: 6 (3\%). Responses to the second question, How did these inclusive problems make you feel? showed that most students felt neutral about them MC responses: Very Comfortable: 40 (22\%), Somewhat Comfortable: 17 (9\%); Neutral: 103 (56\%), Somewhat Uncomfortable: 21 (11\%), Very Uncomfortable: 3 (2\%). While more students felt comfortable than uncomfortable ( $31 \%$ vs. $13 \%$ ), it is notable that the problem set made some students very uncomfortable.

To facilitate comparison between the typical and inclusive problems, the survey presented one of the inclusive homework problems and a matched textbook problem with a similar context:

Textbook: An organization has 10 male and 7 female members. In how many ways can the organization elect a president, vice president, and secretary if all three officers may not be of the same sex?

Homework: A student club focused on diversity is forming a recruitment committee consisting of 7 of its 30 members. 10 of the club's members identify as gay and 5 identify as asexual. How many ways are there to form a recruitment committee which includes at least three members from each of these groups?

The survey then asked Which of the above problems do you think is harder to solve? MC responses: Textbook version: 27 (15\%), Homework version: 43 (23\%), Neither: 114 (62\%) and also Which of the above problems do you prefer overall? MC responses: Textbook version: 40 (22\%), Homework version: 54 (29\%), Neither: 90 (49\%).

\subsection{Reasoning about Specific Problems}

For the follow-up open response question Why do you prefer the version you chose? (open-response), 83 responses were not substantive (e.g., "N/A" or repeating a multiple-choice option without elaboration). However, $95 \%$ of the non-substantive responses preferred neither version, so the question did not apply in the first place.

Of the 94 students who stated a preference in the multiple-choice question, 90 (96\%) wrote substantive explanations. We used the thematic methods described above to analyze students' reasoning, summarized in Table 1, cross-tabulated with multiple-choice selections. The following subsections explain each theme, roughly ordered from most to least supportive. Three responses could not be categorized because they were too vague or inconsistent (e.g., P2 preferred the textbook problem because "It doesn't seem to be as clear as the problem in the homework").

5.2.1 Supported the Homework's LGBTQ-inclusivity. There were 32 students who explained they valued the inclusivity. The approach in the homework matched their sense of modern values ("they injected 2020 's social norms without going over the top," P56), making the problems "fresh" (P111), and "less dated" (P94). Students emphasized the importance of representation for others ("seeing a representation of themselves may make an impact," P124) and for themselves ("As someone who identifies in the LGBTQ+ spectrum, inclusiveness is nice," P66). Students perceived the inclusive problems as making LGBTQ identities "normalized and just a part of everyday life" (P19), and "remind [ing] people [...] that the community exists and is just as much a part of the world as anyone else! :)" (P72). Tone was important:

P160: In my education experience, I have never interacted so casually with gender identities and sexual orientations other than what traditionally has been accepted; I thought that was cool to see.

Another student saw the inclusive wording as "an effort to address how even the language of math questions can serve to reinforce problematic cultural stereotypes" (P105). That the inclusion of LGBTQ identities is notable highlights the exclusion of these identities in typical assignments.

5.2.2 Homework Problem Wording was Clearer. Five students explained that the homework version was easier to understand because of its wording. The textbook was confusing to some because "it says that all three officers may not be of the same sex but only the number of males and females was quantified while the others are not" (P125). While the cis-normative assumptions in the textbook problem may make it clearer for students who expect them, cisnormative text can be less understandable for students who do not hold those assumptions. Others did not pinpoint what made the homework problem clearer.

5.2.3 Reasons Unrelated to Inclusivity. Thirty-six students included reasoning based on other features besides the inclusive wording, or explicitly stated the inclusivity did not matter to them. Fifteen noted mathematical features of the problem (e.g., the number of variables) or of the course resources: "[the textbook includes] references to find the right answer" (P106), "more similar to the example that we have solved in lecture set” (P39). Sixteen students noted the level of difficulty or clarity without explaining if the inclusive wording affected either, e.g.: "Easier" (P49), "the wording of the question better fit the method used to solve it" (P32). Six felt the inclusive language did not impact them personally, but may help others.

Since the first survey question focused on "inclusiveness regarding gender and sexual orientation", and since 28 of these 36 students noticed both the inclusive language and expressed a preference on the multiple-choice question, it is notable that only 6 of them addressed it (to say they did not care). The remaining students may also not have cared at all, or may have thought the inclusive language should be commonplace and that commenting on it would 
Table 1: Themes Crossed with Multiple Choice: a Specific Textbook (Typical) vs. Homework (LGBTQ-Inclusive) Problem

\begin{tabular}{|c|c|c|c|c|c|c|c|}
\hline \multirow{2}{*}{ Open-Response Themes } & \multirow{2}{*}{ Students } & \multicolumn{3}{|c|}{ Preferred Version } & \multicolumn{3}{|c|}{ Feelings on Future Incl. Problems } \\
\hline & & Typical & Neither & Inclusive & Negative & Neutral & Positive \\
\hline Supported homework's LGBTQ-inclusivity & 32 & 0 & 2 & 30 & 1 & 0 & 31 \\
\hline Homework wording was clearer & 5 & 5 & 0 & 0 & 0 & 2 & 3 \\
\hline No preference on inclusive wording & 36 & 14 & 5 & 17 & 4 & 15 & 17 \\
\hline Inclusive wording increased cognitive load & 16 & 12 & 3 & 1 & 5 & 6 & 5 \\
\hline Lacked nuance and/or self-defeating & 9 & 7 & 1 & 1 & 6 & 1 & 2 \\
\hline Opposed LGBTQ-inclusive language in class & 8 & 7 & 1 & 0 & 3 & 5 & 0 \\
\hline Not substantive & 83 & 2 & 79 & 2 & 5 & 50 & 28 \\
\hline Too vague or inconsistent to categorize & 3 & 1 & 1 & 1 & 0 & 2 & 1 \\
\hline Total (8 students have multiple themes) & 184 & 40 & 90 & 54 & 20 & 80 & 84 \\
\hline
\end{tabular}

turn it into a big deal. Others may not have felt comfortable voicing their discomfort with the wording.

5.2.4 Inclusive Wording Increased Extraneous Cognitive Load. For 12 students, the wording of the homework problem made it more difficult. The textbook problem was "less wordy" (P65); "simpler and shorter" (P9). (The textbook problem is 34 words and the homework problem is 52 words.) Other students addressed the content, saying the homework problem includes "unneeded details" (P3) and "more fluff" (P31). Some students reflected that the cisnormativity in the textbook problem made it easier to understand because it was more familiar, e.g., "[...] less people are familiar with those group types which kind of adds an unfamiliarity with the question material psychologically" (P170), "[...] I think it is much easier to acknowledge the difference when you say male and female subconsciously rather than gay or asexual because we didn't hear than in book ever throughout my schooling" (P102), and "I did notice myself getting a bit distracted on homework 5 when I was writing the problem out due to the different nature of it being more inclusive. I don't think that is a bad thing just something that caught my attention" (P173).

These responses point to an additional cognitive load [27] of the inclusive problems: for students who are unfamiliar with terms like asexual, understanding the text takes extra effort that is unrelated to learning the mathematics. For this problem, students must also realize that gay and asexual are exclusive in this context, and that the sexual orientations of the other club members are not relevant. Even for students familiar with inclusive language, seeing LGBTQ representation in a mathematics context may be unexpected, and therefore require more cognitive resources to process.

5.2.5 Inclusive Problems Lacked Nuance and/or were Self-defeating. Nine students thought our implementation was heavy-handed, e.g.: "trying too hard to be 'inclusive" " (P5), "far too 'in-your-face", (P41) and self-defeating, e.g.: "I personally feel that the inclusion of underrepresented groups felt a bit forced, in a way that would not benefit the community, and just felt a bit awkward" (P68). Three of these students interpreted the homework problem as recommending that the recruitment committee include disproportionately more gay and asexual members than the club as a whole, and called this "amusing" (P3), "a little strange" (P109), and that "trying to select LGBTQ members specifically in questions is further discrimination towards the LGBTQ community" (P155). These responses did not overtly oppose inclusion in general, but did recommend more subtlety.

Only one student in this category preferred the homework problem, and this student recommended "focusing on what the members are doing instead of what they are" (P119). This student selfidentified as bisexual and noted "I'm not sure if I would be $100 \%$ onboard if somebody wanted to identify me as an unnamed bisexual in a homework problem. Sexuality is one part of many changing aspects of a person's identification of themselves."

5.2.6 Opposed Seeing LGBTQ-inclusive Language in Class. There were 8 students who expressed discomfort with the inclusive language without suggesting that modifying the problems might alleviate it. Some did not want to engage with LGBTQ material, e.g., "I am just uncomfortable with the subject" (P57), "I just don't like to think about these issues while I'm focusing on hw", (P154) and saw it as inappropriate for a technical class:

P54: I don't think sexual orientation has anything to do with discreet mathematics. It seems like yet another way to push a certain way of thinking on students when all were trying to do is learn math. Why can't you just use examples that aren't conflictive?

Others expressed their support for LGBTQ inclusion in general, but opposed the inclusive language in the homework problems:

P4: I have nothing against the LGBTQIA community, I support them. I just felt the last assignment was a bit political and I simply didn't enjoy having it in the mix. Textbook version seems more clean and to-the-point to me.

Another student preferred the textbook problem because it was "More neutral as it does not directly state the sexual orientations" (P154). These responses, even the ones explicitly voicing support for LGBTQ people, position the textbook language of male, female, and sex as neutral (and therefore focused on the mathematics), and the homework problems as non-neutral. That cis- and hetero-normative language is seen as "to-the-point" (P4) and "mathy" (P137), while LGBTQ-inclusive language is seen as "political" (P4), "conflictive" 
(P54), and "out of place" (P137) exemplifies why LGBTQ students feel that they are not welcomed in the computer science community.

Other students were concerned with how they would be perceived when using LGBTQ-related language, and the associated effort of "making sure you're writing about sensitive subjects politely" (P30). One wrote, "[I] don't really want to write something like '3 gays' because that just sounds somewhat demeaning/disrespectful" (P88). Notably, these responses focus on the risks to the writer of being perceived as offensive, rather than the risk of harming other students through disrespectful language.

\subsection{Reasoning about Inclusivity in General}

There were 121 (out of 184) survey respondents who provided a substantive answer to the final open response question: "Any additional feedback for the Discrete Math staff regarding inclusiveness?" Out of those, 103 addressed inclusivity (18 raised other issues such as homework quantity). We analyzed the responses with the same thematic methods described for the previous question. For this question, each response aligned with one theme, so we report the number of students (rather than responses). As the themes here overlap with those in the previous section, we focus on the additional ideas elicited by this question.

5.3.1 Supported Inclusivity. Fifty students praised the effort to improve representation and inclusivity, for generally the same reasons as discussed in Sec. 5.2.1. However, half of these students had not explicitly supported the homework's LGBTQ-inclusive language in the previous open response question. For this question, those students mostly gave high-level praise, like "Keep up the inclusion!" (P95), and supported the goals for others though it did not affect them, e.g., "These types of problems don't bother me so therefore if they help others feel more included I am all for it" (P80), with some cautioning about difficulty, e.g., "the inclusiveness is a good thing, as long as the difficulty of the class is not raised" (P35). The difference in responses between the two questions demonstrates the importance of asking both types: on the specific problems used and on inclusivity broadly. Many who did not have a strong opinion between the two problems or who focused on their difficulty in the first open response still supported the broader goal.

Some students, while supporting the effort overall, also critiqued the language (e.g., responding to question 2 in section 3, P119 applauding the inclusion of intersex alongside male and female, but criticized the phrase biological sex as exclusionary to trans and genderqueer people). This example shows how language that is intended to be inclusive can still miss the mark.

5.3.2 Supported Inclusivity but Suggested Implementation Changes. There were 15 students who supported LGBTQ inclusion in the problem sets in general, but recommended more subtlety in the problem wording and/or sprinkling a few throughout the course rather than having all in one assignment. Eight students described the problem set overall as "forced" (P27, P61, P68, P73, P103, P114, $\mathrm{P} 145)$ or "pandering" (P97). A self-identified lesbian woman explained that while representation was nice in general, too much was uncomfortable:

P147: It's fun, but 'too much representation', at least to me, seems a bit spotlight-y. Personally I really enjoyed the questions and even texted my girlfriend about how cool it was to have some hella gay homework. It's nice to have, but I don't really mind one way or the other. In the future having a few questions sprinkled throughout like the last assignment would be nice.

Hence, while many of these students were just as enthusiastic about the goals as those in the previous category, they encouraged us to "dial it back" (P114) for the comfort of both LGBTQ students and students who may oppose inclusivity - they preferred nods to identity like "Charlie and "her* girlfriend" (P7), not explicit labels.

5.3.3 Abstain or Neutral. Nineteen students held neutral opinions ("I don't have a preference", P125), did not think this type of inclusivity was important but did not oppose it ("I shouldn't matter whether a problem includes lesbian couples or different sexual orientations [...] If you change problems, fine. If you leave them alone, fine", P76), or thought their voices were irrelevant ("You won't have anything interesting from me, as I am a straight and mostly white male. But be sure to be open and receptive to what minority groups have to say!", P133).

5.3.4 Opposed Inclusive Representation. Seventeen students objected to greater LGBTQ inclusion on homework assignments. Some responses suggested it was not useful ("I don't think it is necessary or helps anyone when you put gender identity, race, religion, politics, etc. in a math question." P31), and that it drew the focus away from the mathematics ("I was surprised by the inclusive questions. It honestly distracted me from the $h w$ and made the questions more difficult" P154). Others described the LGBTQ-inclusion on the homework as "controversial" (P32) and "trying to push a political agenda" (P128). These responses recommended that we "remove human elements" (P79) to make the problems neutral. The rhetoric, which is not overtly homophobic, has parallels to colorblind approaches for discussing racism [3], especially the concept that attention to race is racist ("what causes these issues in the first place is how people go out of their way to be inclusive" P122) and narrow conceptions of equal access or opportunity (e.g, P41 explains "inclusiveness means 'everyone is welcome here'. This doesn't mean that 'everyone is celebrated here' [...if] all people have equal access to education, the university is doing its job"). In this view, it is sufficient for LGBTQ students to have equal access to the course materials, even if those course materials are all cis/hetero-normative.

\subsection{Other Aspects of Identity in CS}

Our survey also asked students to select all aspects of their identity which were important to them (from a list of: age, gender, sexual orientation, race/ethnicity, religion/spirituality, political affiliation, and an 'other' option that could be filled). For each listed identity, a multiple-choice question asked How would you say your identity is treated in the CS department, with respect to your <aspect of identity>? with a 5-point scale from Very Maligned to Very Affirmed and an option This aspect of my identity is unimportant to me. The most common selection, for each question, was Neutral. The next most common were Unimportant and Affirmed (collapsing Very and Somewhat) - in that order for race/ethinicity, religion/sprituality, and politics, tied for orientation, and in the reverse order for age and gender. Only one respondent felt Very Maligned for anything 
(their political affiliation). However, across all surveyed aspects of identity, at least one student felt Somewhat Maligned (15 for gender, 13 for race/ethnicity, 8 for politics, 6 for religion/spirituality, 4 for age, and 1 for orientation). Of the 15 students who felt Somewhat Maligned for their gender, 13 self-identified as female/women. Only 33 women participated in the survey; that almost $40 \%$ were uncomfortable in the department is troubling. Of the 33 women, 24 self-identified as straight, and 9 self-identified as lesbian, bi, queer, or asexual (LBQA). The LBQA women were slightly more likely than the straight women to feel Somewhat Maligned for gender (44\% vs. $38 \%$ ). While only one student felt Somewhat Maligned for orientation, that student self-identified as both queer and female, and also felt Somewhat Maligned for gender.

\section{LESSONS LEARNED}

On the whole, students were positive or neutral about LGBTQ representation in their homework. Forty percent (74 students) explicitly supported inclusion on at least one open-response question, and $16 \%$ (30) felt positively toward future inclusive problems (multiplechoice). Only $11 \%$ (21) opposed inclusivity in an open response, and 5\% (9) felt negatively toward future inclusive problems. Hence, student reception to introducing inclusive material will likely be positive overall.

Of the 28 students who self-identified as non-straight or genderqueer, $46 \%$ (13) were explicitly supportive in an open response, and $25 \%$ (7) more felt positively toward future inclusive problems. 3 opposed it in an open response, and 2 more felt negatively toward future inclusive problems. LGBTQ students are not monolithic, and negative responses from them caution us in particular to design materials which truly support the students we are trying to affirm.

\subsection{Designing Inclusive Problems}

Our recommendations respond to students' and instructors' goals that inclusive problems feel natural and do not affect difficulty:

(1) Spread out affirming problems throughout the course, instead of having one affirmation-heavy assignment.

(2) Focus on what the people are doing or use context clues rather than labels alone.

(3) Ensure that the length of the problem statement and the mathematical complexity is aligned with textbook problems.

(4) Consider defining terms that may be unfamiliar, and clarify when identities are exclusive vs. possibly overlapping.

Since affirming problems are still rare, instructors might consider explicitly discussing them early in the course, as described below.

\subsection{Introducing Inclusivity in Class}

Surprise may have exacerbated some students' negative reactions to the inclusive problems. Rakamaric had not wanted to call extra attention to the inclusive problems, believing that they should not be noteworthy. However, such problems are noteworthy because of how rare they are; in retrospect, introducing them may have helped. Still, an instructor's discussion of inclusivity must not feel forced or put an uncomfortable spotlight on minorities. One strategy is to discuss inclusivity when reviewing the syllabus. At our university, syllabi often include a boilerplate diversity statement. The instructor could explain what respecting diversity means in their class, including policies for missing class for religious observances, honoring students' names and pronouns, etc. The instructor could point out that the book uses cis/hetero-normative assumptions, but that course problems will be diverse and course staff welcome student feedback on inclusivity. Mentioning inclusive problems alongside other policies for diversity may strike a balance of providing context but not being heavy handed.

6.2.1 Concerns about Inclusive Problems. Several straight/cis students who counted themselves as allies seemed uncomfortable with LGBTQ inclusivity in their homework out of concern that they might accidentally say something offensive. Similar concerns might silence otherwise inclusive STEM professors, who fear they do not know the best way to address concerns with heteronormativity or gender bias in course curriculum. However, the fact that even the most well-meaning allies will occasionally make mistakes should not prevent us from striving to make our learning environments more inclusive and affirming of LGBTQ students. In this regard, instructors can model respect by soliciting feedback and treating it as an opportunity to learn and improve.

Instructors may also be concerned that some students will feel that affirming problems are uncomfortable, political, or inappropriate for a math class. About $11 \%$ of our surveyed students (21/184) opposed the inclusive language for these or similar reasons (in an open response). Students may not recognize the degree of cis/heteronormativity in traditional word problems, because those assumptions are taken for granted and seen as neutral. This perspective results from the lack of broad representation in STEM classes in general, and is part of what makes CS feel uncomfortable for marginalized groups. While negative reactions were much less common than positive ones, instructors should be prepared for them.

\subsection{Women in Computer Science}

Nearly $40 \%$ of women respondents (13/33) felt "Somewhat Maligned" in the department regarding their gender. Their opinions on LGBTQinclusivity indicate that female CS students who feel maligned for their gender may also benefit from inclusive coursework design; 12 wanted to see more inclusive problems in the future (1 was neutral) and 8 explicitly supported inclusivity in an open response (none opposed it). A self-identified straight, cis-woman wrote "Many of my friends are a part of the LGBTQ+ community, so it's nice to see problems that are inclusive of their community!" (P126). Further, gender and sexual orientation intersect; women who are also sexual minorities may feel unwelcome along both dimensions. Inclusive representation may be particularly important for them.

\section{CONCLUSIONS AND NEXT STEPS}

We developed and deployed a homework assignment featuring combinatorics problems designed to affirm LGBTQ identities in the University of Utah's discrete mathematics course. We take students' positive reactions as a sign of success. Still, some students seemed to oppose inclusivity, highlighting the need for it. Based on students' suggestions and our lessons learned, we plan to spread affirming content throughout the course. As an additional strategy for abstract or numerical problems, we are incorporating historical factoids about relevant mathematicians in footnotes, to point students to a set of diverse (and often lesser-known) thinkers. 


\section{ACKNOWLEDGMENTS}

This work was supported in part by the National Science Foundation (NSF) awards CCF 1552975 and DGE 2041960. We thank Shelby Hearn from the University of Utah LGBT Resource Center for providing us with resources that were helpful in crafting of our survey.

\section{REFERENCES}

[1] James A. Banks. 2010. Approaches to Multicultural Curriculum Reform. In Multicultural Education: Issues and Perspectives (7th ed.), James A. Banks and Cherry A. McGee Banks (Eds.). Wiley, Chapter 10, 233-256.

[2] Emilie Barnard, Andrea Russo, and Gustavo Arriaga. 2021. Purposeful Plans for Computer Science Diversity, Equity, and Inclusion. Association for Computing Machinery, New York, NY, USA, 1362. 10.1145/3408877.3439529

[3] Eduardo Bonilla-Silva. 2018. Racism without Racists: Color-Blind Racism and the Persistence of Racial Inequality in America (5th ed.). Rowman \& Littlefield Publishers.

[4] Virginia Braun and Victoria Clarke. 2012. Thematic Analysis. In The Handbook of Research Methods in Psychology, H. Cooper (Ed.). American Psychological Association, Washington, DC, Chapter 4, 57-71. https://doi.org/10.1037/13620004

[5] Hilary Burdge, Shannon Snapp, Carolyn Laub, Stephen T. Russel, and Raymond L. Moody. 2013. Implementing Lessons that Matter: The Impact of LGBTQ-Inclusive Curriculum on Student Safety, Well-Being, and Achievement. San Francisco, CA Gay-Straight Alliance Network and Tucson, AZ: Frances McClelland Institute for Children, Youth, and Families at the University of Arizona. https://gsanetwork. org/wp-content/uploads/2018/08/Implementing_Lessons.pdf

[6] Erin A. Cech and William R. Rothwell. 2018. LGBT Inequality in Engineering Education. Fournal of Engineering Education 107, 4 (2018), 583-610. https: //doi.org/10.1002/jee.20239

[7] The Center. 2017. Information and Data Collection Involving Gender and Sexu ality. https://www.kings.uwo.ca/kings/assets/File/research/rerc/Andrew3ia AskingaboutGenderandSexuality.pdf

[8] Michele DiPietro. 2009. Diversity Content as a Gateway to Deeper Learning: The Statistics of Sexual Orientation. Diversity \& Democracy 12, 3 (2009). https://www.aacu.org/publications-research/periodicals/diversitycontent-gateway-deeper-learning-statistics-sexual

[9] Douglas E. Ensley and J. Winston Crawley. 2006. Discrete Mathematics: Mathematical Reasoning and Proof with Puzzles, Patterns, and Games. Wiley, New York, NY.

[10] Jonathan B. Freeman. 2020. Measuring and Resolving LGBTQ Disparities in STEM. Policy Insights from the Behavioral and Brain Sciences 7, 2 (2020), 41-48. https://doi.org/10.1177/2372732220943232

[11] GSLEN. 2019. School Climate for LGBTQ Students in Utah. https://www.glsen org/sites/default/files/2021-01/Utah-Snapshot-2019.pdf

[12] Public Religion Research Institute. 2017. American Values Atlas. http://ava.prri. org/\#lgbt/2017/States/lgbt ssm/m/US-UT

[13] Justin Li. 2017. Weaving Diversity and Inclusion into CS Content (Abstract Only). In Proceedings of the 2017 ACM SIGCSE Technical Symposium on Computer Science
Education (Seattle, Washington, USA) (SIGCSE '17). Association for Computing Machinery, New York, NY, USA, 726. https://doi.org/10.1145/3017680.3022358

[14] Amanda Menier, Rebecca Zarch, and Stacey Sexton. 2021. Broadening Gender in Computing for Transgender and Nonbinary Learners. 2021 Research on Equity and Sustained Participation in Engineering, Computing, and Technology (RESPECT) (2021).

[15] Laura Moorhead. 2018. LGBTQ+ visibility in the K-12 curriculum. Phi Delta Kappan 100, 2 (2018), 22-26. https://doi.org/10.1177/0031721718803565

[16] Jaye Nias. 2021. Educational Programming Practices that Inspires Change: Social Justice as Situated in a Computer Programming Course. 2021 Research on Equity and Sustained Participation in Engineering, Computing, and Technology (RESPECT) (2021).

[17] Sara B. Oswalt and Tammy J. Wyatt. 2011. Sexual Orientation and Differences in Mental Health, Stress, and Academic Performance in a National Sample of U.S. College Students. Fournal of Homosexuality 58, 9 (2011), 1255-1280. https: //doi.org/10.1080/00918369.2011.605738

[18] Manuel A. Pérez-Quiñones. 2020. How to Become Fluent in Diversity and Inclusion in One Evening. In Proceedings of the 51st ACM Technical Symposium on Computer Science Education (Portland, OR, USA) (SIGCSE '20). Association for Computing Machinery, New York, NY, USA, 1392. https://doi.org/10.1145/ 3328778.3367020

[19] Kathleen Rands. 2009. Mathematical Inqu[ee]ry: Beyond 'Add-Queers-and-Stir' Elementary Mathematics Education. Sex Education 9, 2 (2009), 181-191. https: //doi.org/10.1080/14681810902829646 arXiv:10.1080/14681810902829646

[20] Sue Rankin and Jason C. Garvey. 2015. Identifying, Quantifying, and Operationalizing Queer-Spectrum and Trans-Spectrum Students: Assessment and Research in Student Affairs. New Directions for Student Services 2015, 152 (2015), 73-84. https://doi.org/10.1002/ss.20146

[21] Kristen Renn. 2017. LGBTQ Issues on Campus: Issues and Opportunities for Higher Education Leaders. Higher Education Today (2017). https://www. higheredtoday.org/2017/04/10/lgbtq-students-higher-education

[22] Trysten S Richard, Zvonimir Rakamaric, and Eliane S. Wiese. 2021. soarlab/lgbtqproblem-set: LGBTQ Problem Set v1.0.2. https://doi.org/10.5281/zenodo.5750770

[23] Heather Ridolfo, Kristen Miller, and Aaron Maitland. 2012. Measuring Sexual Identity Using Survey Questionnaires: How Valid Are Our Measures? Sexuality Research Social Policy 9 (2012), 113-124. https://doi.org/10.1007/s13178-0110074-x

[24] Allison Scott, Fraeda Kapor Klein, and Uriridiakoghene Onovakpuri. 2017. Tech Leavers Study. Technical Report. Kapor Center for Social Impact.

[25] Shannon Snapp, Hilary Burdge, Adela C. Licona, Raymond L. Moody, and Stephen T. Russel. 2015. Students' Perspectives on LGBTQ-Inclusive Curriculum. Equity and Excellence in Education 48, 2 (2015), 249-265. https: //doi.org/10.1080/10665684.2015.1025614

[26] Jane G. Stout and Heather M. Wright. 2016. Lesbian, Gay, Bisexual, Transgender, and Queer Students' Sense of Belonging in Computing: An Intersectional Approach. Computing in Science Engineering 18, 3 (2016), 24-30. https: //doi.org/10.1109/MCSE.2016.45

[27] John Sweller. 1994. Cognitive load theory, learning difficulty, and instructional design. Learning and Instruction 4, 4 (1994), 295-312. https://doi.org/10.1016/ 0959-4752(94)90003-5

[28] Jessica Zeitz and Karen Anewalt. 2021. Creating a Repository of Diversity and Inclusion Assignments for Computer Science. Association for Computing Machinery, New York, NY, USA, 1321. 10.1145/3408877.3439654 